\title{
GROWTH OF SUBHARMONIC FUNCTIONS OF ORDER GREATER THAN HALF
}

\author{
Seid Mohammed
}

Department of Mathematics, Faculty of Science, Addis Ababa University

PO Box 1176, Addis Ababa, Ethiopia. E-mail: seid_m@math.aau.edu.et

\begin{abstract}
In this paper we shall study the growth and asymptotic behaviour of sub-harmonic functions of order greater than half near Pólya peaks. In some way our result is a generalization of Paley's conjecture. The method employed is a non-asymptotic via a normal family of subharmonic functions.
\end{abstract}

Key words/phrases: Order, Pólya peaks, star function, subharmonic

\section{INTRODUCTION}

Let $\mathrm{u}$ be a subharmonic function defined on the complex plane $\mathrm{C}$. We set

$$
\mathrm{B}(\mathrm{r}, \mathrm{u})=\sup _{|z|=r} \mathrm{u}(\mathrm{z})
$$

and define the Nevanlinna characteristic of $\mathrm{u}$ by

$$
\mathrm{T}(\mathrm{r}, \mathrm{u})=\frac{1}{2 \pi} \int_{0}^{2 \pi} \mathrm{u}^{+}\left(\mathrm{re}^{\mathrm{i} \theta}\right) \mathrm{d} \theta
$$

where $\mathrm{u}^{+}(\mathrm{z})=\max (\mathrm{u}(\mathrm{z}), 0)$.

The lower order $\lambda$ of $u$ is given by

$$
\lambda=\underline{\lim } \frac{T(r, u)}{\log r}
$$

A sequence $\left\{r_{n}\right\}$ of positive numbers is said to be a sequence of Pólya peaks for $\mathrm{T}(\mathrm{r}, \mathrm{u})$ of order $\lambda>0$ if there is a sequence $\left\{\epsilon_{\mathrm{n}}\right\}, \in_{\mathrm{n}}>0$ such that $\epsilon_{\mathrm{n}} \rightarrow 0$ and $\in_{\mathrm{n}} \mathrm{r}_{\mathrm{n}} \leq \mathrm{t} \leq \in_{n}^{-1} \mathrm{r}_{\mathrm{n}}$ imply

$$
\mathrm{T}(\mathrm{t}, \mathrm{u}) \leq\left(1+\epsilon_{\mathrm{n}}\right)\left(\frac{t}{r_{n}}\right)^{\lambda} \mathrm{T}\left(\mathrm{r}_{\mathrm{n}}, \mathrm{u}\right) .
$$

It is well known that $\mathrm{T}(\mathrm{r}, \mathrm{u})$ has a sequence of Pólya peaks of lower order $\lambda>0$ (see Edrei, 1965). It is also easy to see that a subsequence of Pólya peaks for $\mathrm{T}(\mathrm{r}, \mathrm{u})$ is also a sequence of Pólya peaks for $\mathrm{T}(\mathrm{r}, \mathrm{u})$.

Let $\mathrm{u}$ be a subharmonic function of lower order $\lambda>1 / 2$ and $\left\{r_{n}\right\}$ be a sequence of Pólya peaks for $\mathrm{T}(\mathrm{r}, \mathrm{u})$. We will prove that

$$
\varlimsup \frac{B\left(r r_{n}, u\right)}{T\left(r_{n}, u\right)} \leq \pi \lambda \mathrm{r}^{\lambda}, 0<\mathrm{r}<\infty .
$$

For $\mathrm{r}=1$, (1) is Paley's conjecture (Paley, 1932) and, for its proof see Rossi and Weitsman (1983) in case $u=\log |f|$ where $f$ is an entire function.

The subharmonic function

$$
\mathrm{u}\left(\mathrm{re}^{\mathrm{i}}{ }^{\theta}\right)= \begin{cases}\pi \lambda r^{\lambda} \cos \lambda \theta,|\theta| \leq \frac{\pi}{2 \lambda} \\ 0 & \text { otherwise }\end{cases}
$$

satisfies $\mathrm{T}(\mathrm{r}, \mathrm{u})=\mathrm{r}^{\lambda}, \mathrm{B}(\mathrm{r}, \mathrm{u})=\pi \lambda \mathrm{r}^{\lambda}$ and is extremal for (1), i.e., equality holds in (1). We will show that subharmonic functions of lower order $\lambda>1 / 2$, for which equality holds in (1) for some $r>0$, behave asymptotically as rotations of the function given in (2). Indeed we have the following theorem.

\section{Theorem 1}

Let $\mathrm{u}$ be a subharmonic function of lower order $\lambda>1 / 2$ and $\left\{\mathrm{r}_{\mathrm{n}}\right\}$ a sequence of Pólya peaks for $\mathrm{T}(\mathrm{r}, \mathrm{u})$ of order $\lambda$. Then the following statements hold:

$$
\text { a) } \quad \varlimsup \quad \frac{B\left(r r_{n}, u\right)}{T\left(r_{n}, u\right)} \leq \pi \lambda \mathrm{r}^{\lambda} \quad(0<\mathrm{r}<\infty) \text {. }
$$

b) If equality holds in (a) for some $r>0$ then equality holds for all $\mathrm{r}>0$.

c) $\quad \lim _{n \rightarrow \infty} \frac{T\left(r r_{n}, u\right)}{T\left(r_{n}, u\right)}=\mathrm{r}^{\lambda}, \quad(0<\mathrm{r}<\infty)$.

d) There is a subsequence $\left\{r_{n_{k}}\right\}$ of $\left\{\mathrm{r}_{\mathrm{n}}\right\}$ such that $\mathrm{u}\left(\mathrm{r} r_{n_{k}} \mathrm{e}^{\mathrm{e}^{\theta}}\right)=\left(\mathrm{o}(1)+\mathrm{v}\left(\mathrm{re}^{\mathrm{e}^{\theta} \theta}\right)\right) \mathrm{T}\left(r_{n_{k}}, \mathrm{u}\right)$ as $\mathrm{k} \rightarrow \infty$ for almost all $\theta,|\theta-\alpha| \leq \pi / 2 \lambda$, where $\mathrm{v}\left(\mathrm{re}^{\mathrm{i} \theta}\right)=\pi \lambda \mathrm{r}^{\lambda} \cos \lambda(\theta-\alpha), \alpha \in[-\pi, \pi]$.

We remark that if equality holds in (a) for $r=1$ it is proved that (c) holds, (see Edrei and Fuchs, 1976). 


\section{DEFINITIONS AND FACTS}

In this section we assemble some of the definitions and facts pertinent to prove Theorem 1 . Let $\mathrm{u}$ be a subharmonic function in the plane. The *-function of $\mathrm{u}, \mathrm{u}^{*}$ introduced by Baernstein (1974) is defined by

$$
\mathrm{u}^{*}\left(\mathrm{re}^{\mathrm{i} \theta}\right)=\frac{1}{2 \pi} \sup \int_{E} \mathrm{u}\left(\mathrm{re}^{\mathrm{i} \varphi}\right) \mathrm{d} \varphi,(0 \leq \theta \leq \pi, \mathrm{r}>0)
$$

where the supermum is taken over all sets $\mathrm{E} \subseteq[-\pi$, $\pi]$ with $\mathrm{m}(\mathrm{E})=2 \theta(\mathrm{m}=$ Lebesgue measure on the real line). Baernstein (1974) proved that $\mathrm{u}^{*}$ is subharmonic in the upper half plane, $\pi^{+}$and continuous in the closure of $\pi^{+}$except possibly at the origin. Further, $\mathrm{u}^{*}$ also satisfy (see also Hyman, 1989, Chap 9)

$$
\begin{aligned}
& \mathrm{T}(\mathrm{r}, \mathrm{u})=\max _{0 \leq \theta \leq \pi} \mathrm{u}^{*}\left(\mathrm{re}^{\mathrm{i} \theta}\right), \quad \mathrm{u}^{*}(\mathrm{r})=0 \\
& \mathrm{~B}(\mathrm{r}, \mathrm{u})=\left.\pi \frac{\partial}{\partial \theta} \mathrm{u}^{*}\left(\mathrm{re}^{\mathrm{i} \theta}\right)\right|_{\theta}
\end{aligned}
$$

Let $\left\{r_{n}\right\}$ be a sequence of Pólya peaks for $T(r, u)$ of lower order $\lambda>0$. We set

$\mathrm{u}_{\mathrm{n}}\left(\mathrm{re}^{\mathrm{i}}{ }^{\theta}\right)=\frac{u\left(r r_{n} e^{i \theta}\right)}{T\left(r_{n}, u\right)}, \quad(\mathrm{n}=1,2, \ldots)$,

a sequence of subharmonic functions. A well known result due to Anderson and Baernstein (1978) asserts that there is a subharmonic function $\mathrm{v}$ and a subsequence $\left\{r_{n_{k}}\right\}$ of $\left\{\mathrm{r}_{\mathrm{n}}\right\}$ such that

$$
\lim _{k \rightarrow \infty} \int_{0}^{2 \pi}\left|u_{n_{k}}\left(r e^{i \theta}\right)-v\left(r e^{i \theta}\right)\right| d \theta=0 \quad(0<\mathrm{r}<\infty)
$$

and ...

$$
\lim _{k \rightarrow \infty} \frac{T\left(r r_{n_{k}}, u\right)}{T\left(r_{n_{k}}, u\right)}=\lim _{k \rightarrow \infty} \mathrm{T}\left(\mathrm{r}, u_{n_{k}}\right)=\mathrm{T}(\mathrm{r}, \mathrm{v}) \leq \mathrm{r}^{\lambda} \quad(0<\mathrm{r}<\infty) .
$$

In this paper any subharmonic function $\mathrm{v}$ which satisfies (4) for some subsequence of $\left\{r_{n}\right\}$ will be referred as a limit function of $\left\{u_{n}\right\}$.

We also need the well-known convolution inequality due to Petrenko (1969). Let $u$ be a subharmonic function in the plane, $0<\gamma<1$, we set

$$
\mathrm{k}(\mathrm{t}, \gamma)=\gamma^{-2} \frac{t^{1 / \gamma}}{\left(t^{1 / \gamma}+1\right)^{2}}
$$

We have Petrenkós inequality

$$
\begin{aligned}
\mathrm{B}(\mathrm{r}, \mathrm{u}) \leq & \int_{0}^{R} u *\left(\mathrm{t}^{\mathrm{i} \mathrm{ir}}\right) \mathrm{k}\left(\frac{r}{t}, \gamma\right) \frac{d t}{t} \\
& +\mathrm{C}\left(\frac{r}{R}\right)^{\frac{1}{\gamma}} \mathrm{T}(2 \mathrm{R}, \mathrm{u}),\left(0<r<\frac{R}{2}\right)
\end{aligned}
$$

for an absolute constant $\mathrm{C}$.

Proofs of the above inequality are also given by Essén (1975) and by Edrei and Fuchs (1976) where it was shown that the Mellin transform of $\mathrm{k}(\mathrm{t}, \gamma)$ is

$$
\hat{k}(\mathrm{~s}, \gamma)=\int_{0}^{\infty} \mathrm{k}(\mathrm{t}, \gamma) \frac{d t}{t^{1+s}}=\frac{\pi \mathrm{s}}{\sin \pi \gamma s},\left(0<\mathrm{s}<\frac{1}{\gamma}\right) .
$$

\section{Proof of Theorem 1}

\section{Lemma}

Let $\mathrm{u}$ be a subharmonic function of lower order $\lambda>$ 0 and $\left\{r_{n}\right\}$ a sequence of Pólya peaks for $T(r, u)$ of order $\lambda$. Then there is limit function $v$ of $\left\{u_{n}\right\}$. Such that

$$
\varlimsup \lim B\left(r, u_{n}\right)=B(r, v)
$$

Proof.

Let $\mathrm{w}$ be any limit function of $\left\{\mathrm{u}_{n}\right\}$. Then there is a subsequence $\left\{u_{n_{k}}\right\}$ of $\left\{u_{n}\right\}$ for which (4) holds.

Let $\mathrm{r}>0$ be fixed and $\mathrm{B}\left(\mathrm{r}, u_{n_{k}}\right)=u_{n_{k}}\left(r e^{\beta_{k}}\right)(\mathrm{k}=$ $1,2, \ldots)$ and assume $\beta_{\mathrm{k}} \rightarrow \beta$ as $\mathrm{k} \rightarrow \infty$. Let $0<\mathrm{t}<\mathrm{r}$ and $\mathrm{B}(\mathrm{t}, \mathrm{w})=\mathrm{w}\left(\mathrm{te}^{\mathrm{i} \alpha}\right)$. Then we have

$$
\begin{aligned}
& \mathrm{B}(\mathrm{t}, \mathrm{w}) \leq \frac{1}{2 \pi} \int_{0}^{2 \pi} w\left(r e^{i \theta}\right) P_{t / r}(\theta-\alpha) \mathrm{d} \theta \\
& =\lim _{k \rightarrow \infty} \frac{1}{2 \pi} \int_{0}^{2 \pi} u_{n_{k}}\left(r e^{i \theta}\right) P_{t / r}(\theta-\alpha) \mathrm{d} \theta \leq \longdiv { \operatorname { l i m } } \mathrm { B } ( \mathrm { r } , u _ { n _ { k } } )
\end{aligned}
$$

where

$$
\mathrm{P}_{\mathrm{s}}(\theta)=\frac{1-s^{2}}{1+s^{2}-2 s \cos \theta} \text { is the Poisson kernel. }
$$

Thus $\mathrm{B}(\mathrm{t}, \mathrm{w}) \leq \varlimsup_{\lim } \mathrm{B}\left(\mathrm{r}, u_{n_{k}}\right)$ holds for $\mathrm{t}<\mathrm{r}$. Since $B(s, v)$ is a continuous function of $s$, letting $t \rightarrow r$ we have

$$
\mathrm{B}(\mathrm{r}, \mathrm{w}) \leq \varlimsup \lim \mathrm{B}\left(\mathrm{r}, u_{n_{k}}\right)
$$

On the other hand for $\mathrm{t}>\mathrm{r}$ we have

$$
\mathrm{B}\left(\mathrm{r}, u_{n_{k}}\right) \leq \frac{1}{2 \pi} \int_{0}^{2 \pi} u_{n_{k}}\left(t e^{i \theta}\right) P_{r / t}\left(\theta-\beta_{\mathrm{k}}\right) \mathrm{d} \theta .
$$

Consequently, 


$$
\begin{aligned}
& \varlimsup \mathrm{\operatorname {lim }} \mathrm{B}\left(\mathrm{r}, u_{n_{k}}\right) \leq \overline{\lim } \frac{1}{2 \pi} \int_{0}^{2 \pi} u_{n_{k}}\left(t e^{i \theta}\right) P_{r / t}\left(\theta-\beta_{\mathrm{k}}\right) \mathrm{d} \theta \\
& =\lim _{k \rightarrow \infty} \frac{1}{2 \pi} \int_{0}^{2 \pi} u_{n_{k}}\left(t e^{i \theta}\right) P_{r / t}\left(\theta-\beta_{\mathrm{k}}\right) \mathrm{d} \theta \\
& =\frac{1}{2 \pi} \int_{0}^{2 \pi} w\left(t e^{i \theta}\right) P_{r / t}(\theta-\beta) \mathrm{d} \theta \\
& \leq \mathrm{B}(\mathrm{t}, \mathrm{w})
\end{aligned}
$$

Letting $\mathrm{t} \rightarrow \mathrm{r}$, we have

$\varlimsup \lim \mathrm{B}\left(\mathrm{r}, u_{r_{k}}\right) \leq \mathrm{B}(\mathrm{r}, \mathrm{w})$.

Thus from (7) and (8)

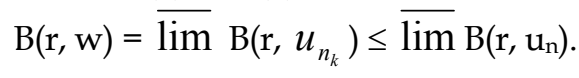

To complete the proof of the Lemma, let $\left\{u_{n_{k}}\right\}$ be a subsequence of $\left\{u_{n}\right\}$ such that

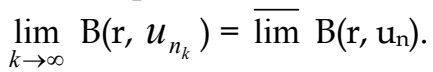

Since $\left\{r_{n_{k}}\right\}$ is a subsequence of Pólya peaks, it is a sequence of Pólya peaks for $\mathrm{T}(\mathrm{r}, \mathrm{u})$. Following the above argument and by (9) there is limit function $\mathrm{v}$ of $\left\{u_{n_{k}}\right\}$ such that

$$
\mathrm{B}(\mathrm{r}, \mathrm{v})=\lim _{k \rightarrow \infty} \mathrm{B}\left(\mathrm{r}, u_{n_{k}}\right)=\varlimsup \lim \mathrm{B}\left(\mathrm{r}, \mathrm{u}_{\mathrm{n}}\right) \text {. }
$$

Now if $u$ is a subharmonic function of lower order $\lambda>1 / 2$ and $v$ is any limit function of $\left\{u_{n}\right\}$ we have by (3) and (4)

$$
\mathrm{v}^{*}\left(\mathrm{re}^{\mathrm{i}}\right) \leq \mathrm{T}(\mathrm{r}, \mathrm{v}) \leq \mathrm{r}^{\lambda}, \quad 0 \leq \theta \leq \pi / 2 \lambda .
$$

Since $\mathrm{v}^{*}(\mathrm{r})=0$ and $\mathrm{v}^{*}\left(r e^{i \pi / 2 \lambda}\right) \leq \mathrm{r}^{\lambda}$, by Phragmén Lindelöf Principle we conclude that

$$
\mathrm{v}^{*}\left(\mathrm{re}^{\mathrm{i} \theta}\right) \leq \mathrm{r}^{\lambda} \sin \lambda \theta, 0 \leq \theta \leq \pi / 2 \lambda .
$$

Consequently by (3)

$$
\mathrm{B}(\mathrm{r}, \mathrm{v})=\pi \frac{\partial v^{*}}{\partial \theta}\left(\mathrm{re}^{\mathrm{i} \theta}\right) \mid \theta=0 \leq \pi \lambda \mathrm{r}^{\lambda} \text {. }
$$

Thus by the Lemma,

$$
\varlimsup \mathrm{lim}\left(\mathrm{r}, \mathrm{u}_{\mathrm{n}}\right) \leq \pi \lambda \mathrm{r}^{\lambda} \quad(0<\mathrm{r}<\infty) \text {. }
$$

This proves assertion (a) of Theorem 1.

\section{Theorem 2}

Let $\mathrm{u}$ be a subharmonic function of lower order $\lambda>1 / 2$ and $\left\{r_{n}\right\}$ a sequence of Pólya peaks for $\mathrm{T}(\mathrm{r}, \mathrm{u})$ of order $\lambda$. If for some $\mathrm{r}_{1}>0 \varlimsup \overline{\lim } \mathrm{B}\left(\mathrm{r}_{1}, \mathrm{u}_{\mathrm{n}}\right)=$ $\pi \lambda r_{1}^{\lambda}$, then there is a limit function $v$ of $\left\{u_{n}\right\}$ such that i)

$\mathrm{v}^{*}\left(\mathrm{re}^{\mathrm{i} \theta}\right)=\mathrm{r}^{\lambda} \sin \lambda \theta, \quad 0 \leq \theta \leq \pi / 2 \lambda, \mathrm{r}>0$ and consequently

$$
\mathrm{T}(\mathrm{r}, \mathrm{v})=\mathrm{r}^{\lambda} \text { and } \mathrm{B}(\mathrm{r}, \mathrm{v})=\pi \lambda \mathrm{r}^{\lambda} \text {. }
$$

ii) $\quad \mathrm{v}\left(\mathrm{re}^{\mathrm{i} \theta}\right)=\pi \lambda \mathrm{r}^{\lambda} \cos \lambda(\theta-\alpha)$ for $|\theta-\alpha| \leq \pi / 2 \lambda$ and for some $\alpha \in[-\pi, \pi]$.

Proof.

By the Lemma there is a subharmonic function $\mathrm{v}$ such that

$$
\varlimsup \lim \mathrm{B}\left(\mathrm{r}, \mathrm{u}_{\mathrm{n}}\right)=\mathrm{B}(\mathrm{r}, \mathrm{v}) \text {. Since } \varlimsup \lim \mathrm{B}\left(r_{1}, \mathrm{u}_{\mathrm{n}}\right)=\pi \lambda \mathrm{r}_{1}^{\lambda},
$$

we have $\mathrm{B}\left(\mathrm{r}_{1}, \mathrm{v}\right)=\pi \lambda \mathrm{r}_{1}^{\lambda}$, applying Peteronko's inequality (5) with $\gamma=1 / 2 \lambda$ and using (6) we obtain

$$
\begin{aligned}
\pi \lambda \mathrm{r}_{1}^{\lambda} & =\mathrm{B}\left(\mathrm{r}_{1}, \mathrm{v}\right) \leq \int_{0}^{\infty} v^{*}\left(t e^{\frac{i \pi}{2 \lambda}}\right) \mathrm{k}\left(\frac{r_{1}}{t}, \lambda\right) \frac{d t}{6} . \\
& \leq \int_{0}^{\infty} t^{\lambda} k\left(\frac{r_{1}}{t}, \gamma\right) \frac{d t}{6} \\
& =\pi \lambda \mathrm{r}_{1}^{\lambda}
\end{aligned}
$$

Hence equality holds through out in (11), which implies

$$
\mathrm{v}^{*}\left(t e^{i \pi / 2 \lambda}\right)=\mathrm{t}^{\lambda}, \quad(0<\mathrm{t}<\infty) .
$$

Since $\mathrm{v}^{*}\left(\mathrm{te}^{\mathrm{i}}{ }^{\theta}\right) \leq \mathrm{T}(\mathrm{t}, \mathrm{v}) \leq \mathrm{t}^{\lambda}$, it follows that $\mathrm{T}(\mathrm{t}, \mathrm{v})=\mathrm{t}^{\lambda}$.

Let $0<\alpha<\pi / 2 \lambda, \gamma=\alpha / \pi<1$ and apply (5) to get $\mathrm{v}^{*}\left(\mathrm{te}^{\mathrm{i} \alpha}\right)=\mathrm{t}^{\lambda} \sin \lambda \alpha$.

Since $\mathrm{v}^{*}\left(\mathrm{te}^{\mathrm{i} \theta}\right) \leq \mathrm{t}^{\lambda} \sin \lambda \theta \quad 0 \leq \theta \leq \pi / 2 \lambda$, it follows by the maximum principle

$$
\mathrm{v}^{*}\left(\mathrm{re}^{\mathrm{i} \theta}\right)=\mathrm{r}^{\lambda} \sin \lambda \theta, 0 \leq \theta \leq \pi / 2 \lambda
$$

which proves (i) of Theorem 2. It follows from (13) and (3) that

$$
\mathrm{B}(\mathrm{r}, \mathrm{v})=\pi \lambda \mathrm{r}^{\lambda} \quad(0<\mathrm{r}<\infty) .
$$

Thus,

$$
\varlimsup \mathrm{lim} B\left(r, u_{n}\right)=\pi \lambda r^{\lambda} \quad(0<r<\infty) .
$$

This proves assertion $(b)$ of Theorem 1 .

Since $\mathrm{v}^{*}(\mathrm{z})$ is harmonic in the region $0<\arg \mathrm{z}<$ $\pi / 2 \lambda$, it follows (Essén and Shea, 1978/79) that

$\mathrm{v}\left(\mathrm{re}^{\mathrm{i} \theta}\right)=\pi \lambda \mathrm{r}^{\lambda} \cos \lambda(\theta-\alpha)$ for $|\theta-\alpha| \leq \pi / 2 \lambda$ and for some $\alpha \in[-\pi, \pi]$.

Assertion (d) of Theorem 1 follows for (4) and an application of results in real analysis. We remark that the above results hold if we replace lower order by order of the subharmonic function. 


\section{REFERENCES}

1. Anderson, J.M. and Baernstein, A. (1978). The size of the set on which a meromorphic function is large II. Proc. London Math. Soc. 36(3):518-539.

2. Baernstein, A. (1974). Integral means, Univalent functions and circular symmetrization II. Acta. Math. 133:139-169.

3. Edrei, A. (1965). Sum of deficiencies of meromorphic function. J. Analyse Math. 14:79-107.

4. Edrei, A. and Fuchs, W.H.J. (1976). Asymptotic behaviour of mermorphic functions with extremal spread. Annales Academiae Series A. I. Matheamticsa 2:67-111.

5. Essén, M. (1975). The cos $\rho$-Theorem. Lect. Note Math. Berlin-Heidelberg, Springer, $467 \mathrm{pp}$.
6. Essén, M. and Shea, D. (1978/79). On some questions in the theory of symmetrization. Annale Academiae scientiarum Fennicae series A.I. Matematica 4:311-340.

7. Hayman, W.K. (1989). Subharmonic Functions, Vol. 2, Academic Press, New York.

8. Paley, A. (1932). Note on integral function. Proc. Cambridge Phill. Soc. 28:262-265.

9. Petrenko, V.P. (1969). The growth of meromorphic functions of finite lower order. Itv. Akad. Nauk USSR 33:414-454.

10. Rossi, J. and Weitsman, A. (1983). A unified approach to certain questions in Value Distribution Theory. J. London Math. Soc. 28(2):310-326. 